\title{
Agricultural Extension in Promoting Household Nutritional Security- Relevant Success Stories
}

\author{
Vijayakhader \\ Department of Foods \& Nutrition, Faculty of Home Science, Acharya N. G. Ranga Agricultural University, Hyderabad, India
}

Email address:

Vijayakhader@gmail.com

To cite this article:

Vijayakhader. Agricultural Extension in Promoting Household Nutritional Security- Relevant Success Stories. Journal of Food and Nutrition Sciences. Vol. 5, No. 5, 2017, pp. 172-178. doi: 10.11648/j.jfns.20170505.12

Received: July 14, 2017; Accepted: July 25, 2017; Published: August 4, 2017

\begin{abstract}
Over 7000 people die of hunger every day. Close to $70 \%$ of women and children suffer from hidden hunger. Most vulnerable sections are adolescent girls, pregnant \& lactating mothers, and underweight children under five age. Malnutrition is both a driver and an outcome of poverty and inequality. Under nutrition leading to stunting causes irreversible damage to both individuals and society. Obesity in childhood is a growing problem in all regions. Ensuring universal access to nutritious food in the 1000-day window of opportunity between the start of pregnancy and a child's second birthday is essential to tackling stunting. This should be supported by a multi-sectoral approach which includes health care, water, sanitation, education, agriculture, social protection and specific nutrition interventions. Intervention of various technologies to improve the food \& nutritional status of the population proved the following facts: Promotion of malt based small scale food industry not only provides opportunity for rural women to develop entrepreneurship and employment, but also provides food and nutritional security through income generation. Several technologies were developed under NATP like value addition to fish \& prawn products, artificial pearl culture, processing of salted fish, which helped the self help group women of Andhra Pradesh, Karnataka, Kerala and Tamil Nadu to improve their economic status. Received two patents \& licensed the technology which helped the women to reduce their drudgery and also preserve the fresh fish for a longer time without getting spoiled. Product development can be taken as income generating activity in the rural areas by the illiterate women. Products can be included in supplementary feeding programs in order to improve the nutritional status of the vulnerable groups of the population. The horse gram which is commonly used for cattle feed can be diversified for human consumption with less investment. Mothers as well as Anganwadi workers preferred amylase rich supplementary foods which reduced Grade 111 and grade 1V malnutrition in Pre- school children significantly. The studies revealed that spawn multiplication can be done by women as a co-operative venture and mushroom cultivation can be undertaken at household level as an income-generating activity. Introducing red palm oil is beneficial to overcome vitamin A deficiency. Impact of women's supplementary income showed a positive impact on the socioeconomic status of the family. This impact is particularly felt on the food and nutrient intake of the family contributing towards food \& Nutrition security.
\end{abstract}

Keywords: Extension Education, Technology Transfer, Food Security, Agricultural Extension, Nutritional Status

\section{Introduction}

Extension is a nonformula educational function that applies to any institution that disseminates information and advice with the intention of promoting knowledge, attitudes, skills and aspirations, although the term "extension" tends to be associated with agriculture and rural development. Extension is multidisciplinary. It combines educational methodologies, communication and group techniques in promoting agricultural and rural \& Public Sector Agricultural
Extension development. It includes technology transfer, facilitation, and advisory services as well as information services and adult education. It is dependent for success on other agricultural development processes such as marketing and credit services, not to mention economic policy and physical infrastructure. In short, it is a function that is dependent for success on other factors, including other services and institutions. In many cases its success depends on the ability to shift program direction and development to stakeholders and program users. Aligning agriculture to 
improve household nutrition security requires agricultural research and development specialists to understand nutrition objectives and be able to contribute to integrated agriculturehealth programs.

The concept of food security developed over the last 50 or more years addressed primarily the need for the production and access to adequate food grains to feed the world's increasing population. Nutrition security, a later development, was a much broader concept since nutritious and safe diets alongside adequate biological and proper social environments ensures appropriate growth and development in childhood and helps promote health and prevent disease in adulthood. The need for a paradigm shift in policy formulation from focusing on food security at the aggregate level to nutrition security at the level of each child and adult implied that the definition 'food and nutrition security' integrates both the conceptual frameworks of food security and nutrition security. This integrated approach aspires not merely to address the micronutrient malnutrition which is a bigger problem than food energy deficiency, but is a foodbased approach that also tackles non-food factors such as water, sanitation and care practices.

Rural employment opportunities should be increased by promoting post harvest opportunities and value addition, entrepreneurship at the village level and this will increase the net income of the farmers. The promotion of agriculture, small scale rural industry, the rural economy gets a big boost and also corrects the rural- urban imbalance and prevents migration.

Food processing has huge potential to dramatically improve rural livelihoods by raising farm incomes through value addition in agricultural produce. "India is home to a wide-range of raw material suited for the food processing industry because of its diverse agro-climatic conditions. A very small percentage of these are processed into value added products at present. So, the scope, potential and opportunities are huge in this industry.

Several Programs: National Nutrition Policy (1993); National Nutrition Plan of Action (1995); National Nutrition Mission (2001) not at achieved nutrition goals. Reasons: Nutrition is a poor cousin even in health and agriculture planning and execution, Nutrition improvement is not a stated goal with measurable parameters in National Food Security Mission, National Horticulture Mission and National Rural Health Mission.

The Most important National Nutrition Programs in India are: Integrated child Development services program (ICDS), The targeted public distribution system (TPDS), Food for work, The National Mid, Day meals program (NMMP), Micro nutrient (Iron folate; Vitamin A; Iodized salt) schemes. Rural employment opportunities s should be increased by promoting post harvest opportunities and value addition, entrepreneurship at the village level and this will increase the net income of the farmers. The promotion of agriculture, small scale rural industry, the rural economy gets a big boost and also corrects the rural- urban imbalance and prevents migration.
In the 21 st century, climate changes, water scarcity, increasing world population, rising food prices, and other socioeconomic impacts are expected to generate a great threat to agriculture and food security worldwide, especially for the poorest people who live in arid and sub arid regions. These impacts present a challenge to scientists and nutritionists to investigate the possibilities of producing, processing, and utilizing other potential food sources to end hunger and poverty. To improve household nutrition security requires agricultural research and development specialists to understand nutrition objectives and be able to contribute to integrated agriculture-health programs.

Research carried out by Vijayakhader: Since the paper deals with the food security, nutrition security, health security and livelihood security, it deals with product development for livelihood and nutritional security; women empowerment for food security and rural development.

\section{Experimental Methodology}

Used starting from Surveys, Chemical analysis, Biochemical estimations, bio-availability studies on rats as well as human subjects; clinical observations and histological studies were used as per the study design. Product development, value addition, Technology transfer, Entrepreneur skills development, income generation activities and creating awareness through Nutrition Education were also used.

\section{Results \& Discussions}

Conceptual frameworks for improving nutrition outcomes have been relatively consistent since 1990, based on an initial framework developed by UNICEF [1]. For example, Figure 1 shows a modification of this framework used by Action Contre La Faim (ACF). ACF applies the nutrition security definition of the World Bank [2] as "the ongoing access to the basic elements of good nutrition, i.e. a balanced diet, safe environment, clean water, and adequate health care (preventive and curative) for all people, and the knowledge needed to care for and ensure a healthy and active life for all household members". This implies that nutritional security goes beyond the traditional concept of food security (access, availability, stability and utilization of food) and recognizes that nutritional status is dependent on a wide and multisectoral array of factors. Another element of the ACF strategy is to apply a mixed strategy of combinations of treatments of acute malnutrition with targeted direct nutrition interventions for immediate impacts, as well as investing in packages of nutrition-sensitive interventions that address the immediate and underlying multi-sectoral determinants of under nutrition [3]. Based on these key principles, the following operational guidelines are used by ACF in planning its nutrition security programs:

The term 'nutrition security', on the other hand, emerged in the mid-1990s and focused on food consumption by the household or the individual and on how that food is utilized 
by the body and thus in principle is more, than food security. A basic impact pathway diagram (Figure 2) was developed. The baseline information provided additional details of options in a few areas. On agricultural production, locally applicable options for increasing production of nutritious foods were made. In addition, the availability of wild/indigenous foods, particularly in hunger periods was noted. Much greater specificity was also developed around infant and young child feeding and care practices, particularly around local production of complementary foods for infants and young children. Finally, the baseline survey also provided ideas for empowering women with different livelihood and income opportunities. The baseline survey and the impact pathways should provide a stronger conceptual basis for understanding and evaluating nutrition-sensitive options in this context. In the impact pathway thinking, particular attention was paid to assessing risk and reducing the chances of introducing harmful change that would adversely impact women, infants and young children.

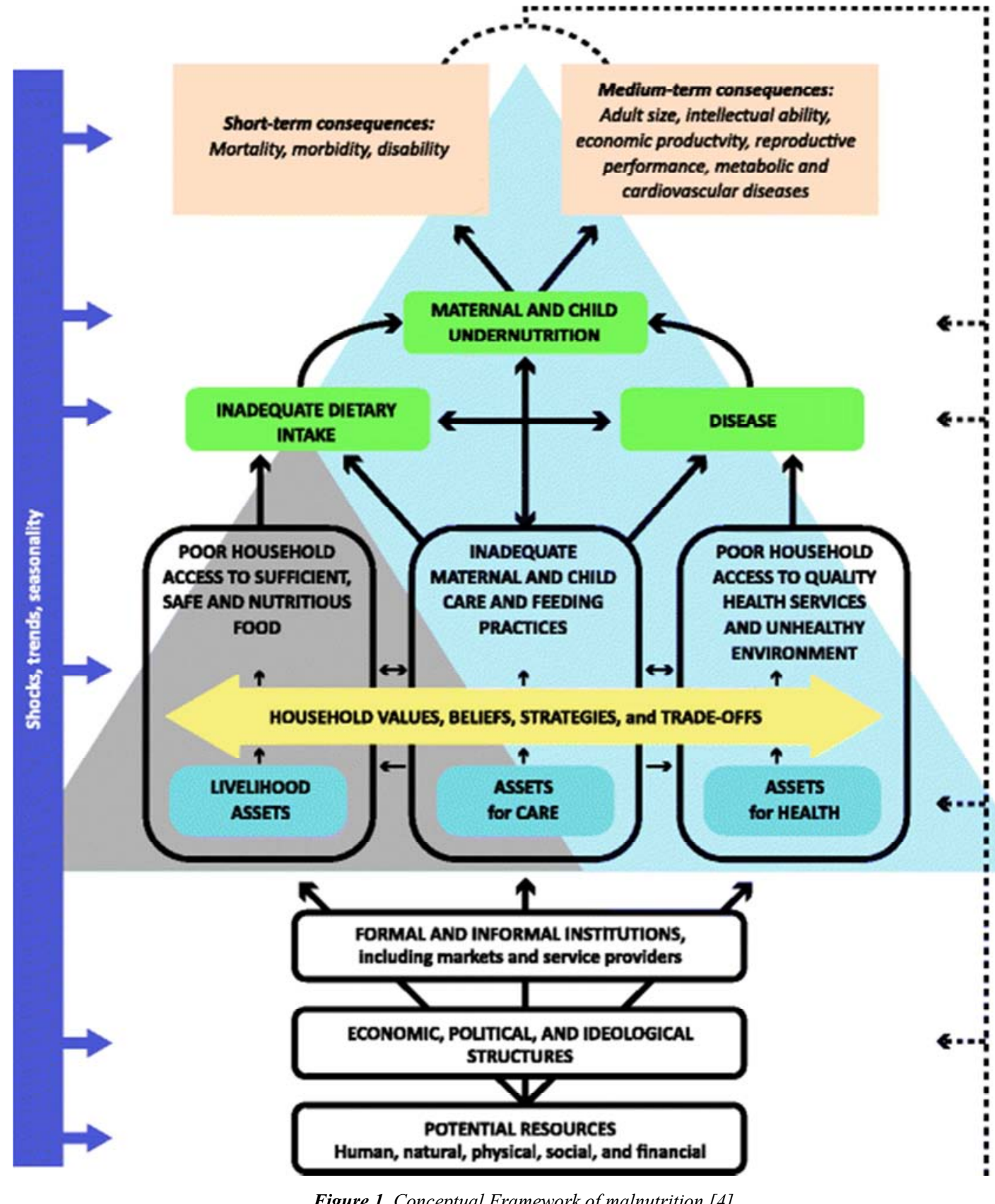

Figure 1. Conceptual Framework of malnutrition [4].

Food Technology can directly contribute to food security through enhancement of nutrient density establishment of tiny cottage scale for processing industry in rural areas would help to empower a rural woman which contributes livelihood security. Value addition/processing is need of the hour. Post harvest management will save the food. 


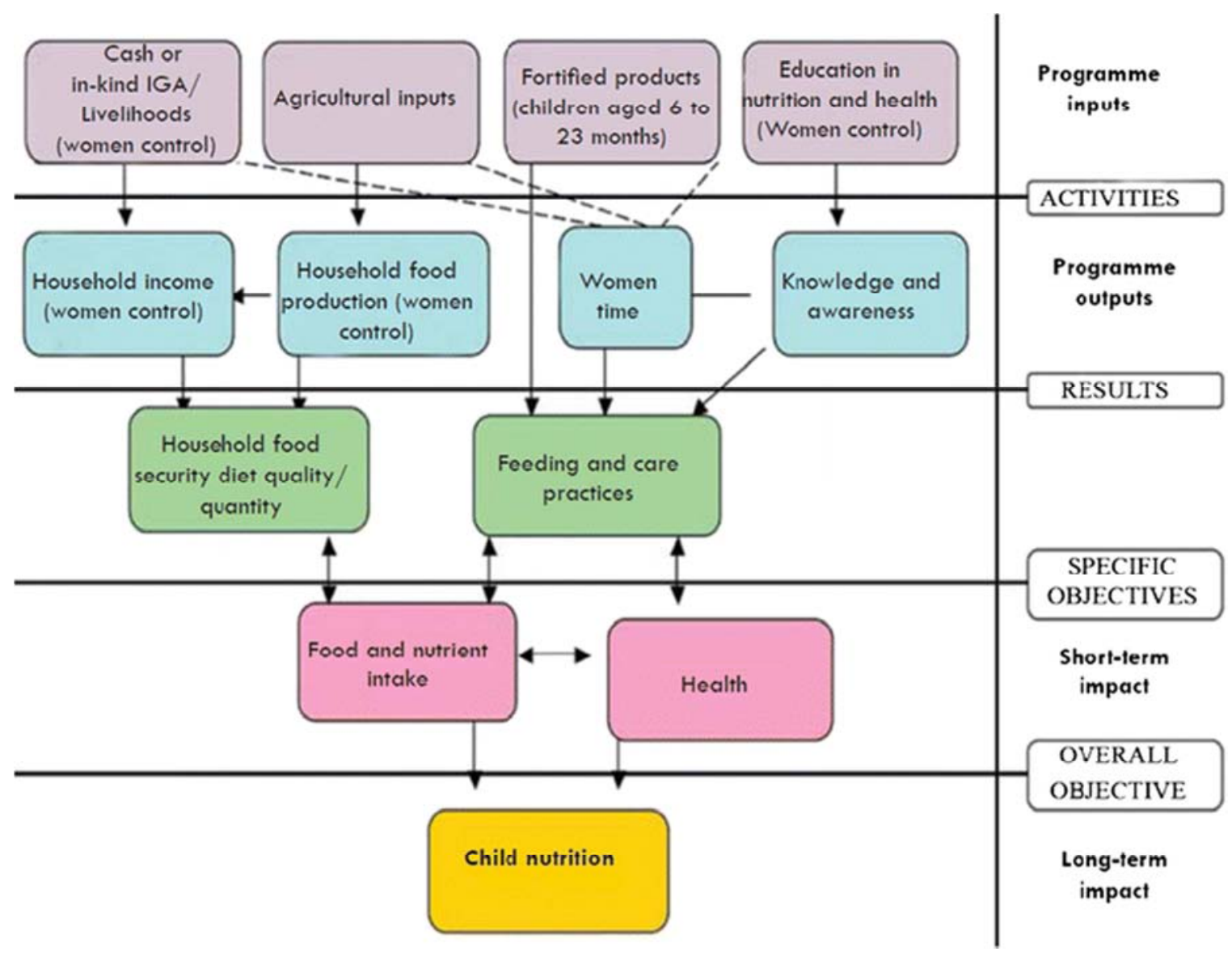

Figure 2. Path ways through which the intervention is expected to affect the nutritional status of the children [5].

Home based low cost energy protein rich preparations using Horse gram for vulnerable groups: The horse gram which is commonly used for cattle feed can be diversified for human consumption with less investment. Processed horse gram flour was prepared using Puffing and Roasting, Processed Soya bean flour was prepared by Dehulling and Roasting. The low cost energy protein rich products namely RAGINA and EPRF were prepared using the simple home scale processing methods like germination, roasting and puffing, to improve the nutritional status. Horse gram has been identified as potential food resource for the tropics and also occupies an important place among pulses because of its ability to resist severe drought conditions. Soya bean (Glycine max) is one of the best vegetable proteins and has tremendous potential to meet the protein deficiency in the cereal based Indian Diets at a low cost. Product development can be taken as income generating activity in the rural areas by the illiterate women. Products can be included in supplementary feeding programs in order to improve the nutritional status of the vulnerable groups of the population [6].

To study the effect of feeding malted food on the nutritional status of vulnerable groups

Amylase Rich Malted Mixes (ARMM) two types were formulated using Ragi / Wheat and suitable products namely Laddu, Roti, Kheer, and Porridge were prepared using formulated malted mix. The ARMM's found to be nutritional dense. For the supplementation of malted mixes 8 villages of Lepakshi Mandal, Ananthapur District was selected. Preschool children (400), pregnant women (100) and Lactating women (100) were selected and fed with two types of malted mixes (Ragi / Wheat) for a period of 3 months. Anthropometric data, Food intake showed a significant increase in the preschoolers, pregnant women and Lactating mothers. Clinical assessment showed considerable reduction i.e. (50\%) in nutritional deficiency symptoms and morbidity rate of all the subjects. Training program were conducted to 40 members by lecture and method demonstrations using developed education material such as Posters, Flip book, Manual and CD-Rom. After the training 60-70\% improvement was observed in Knowledge, Attitude and Practices scores of the trainees, project profile for bulk production was also developed. Supplementation of ARMM's helped to improve the nutritional status of the vulnerable groups of population in rural areas especially with regard to protein, energy, iron, and calcium and B-complex vitamins. Promotion of malt based small scale food industry not only provides opportunity for rural women to develop entrepreneurship and employment but also provided Food and Nutritional Security through income generation. The then Honorable Minister for Agriculture Dr. N. Raghuveera Reddy was very much impressed and interested to introduce ARMM in the ongoing ICDS supplementary feeding programs based on research results [7]. Therapeutic food 
supplementation in ICDS projects of Andhra Pradesh: Total 2267 children of age range of 1-3 years were selected $(892$ children from rural ICDS project, Saravakota; 507 children from new ICDS project, Kottem; and 778 children from tribal ICDS project, Seethapeta) for a period of 1 year. The three types of supplements were prepared and distributed by A. P. Foods, Hyderabad. The supplements were distributed either in the form of Laddu or as in the form of powder. Nutritive value of $100 \mathrm{~g}$ of supplements provides 400 to $480 \mathrm{Kcal} 12.5$ to $13.8 \mathrm{~g}$ proteins.

It was very encouraging to note that $92 \%$ of grade III children showed improvement in their weight and height; $80 \%$ of moderately malnourished; $42 \%$ of mildly malnourished and $44 \%$ with normal grade showed improvement. It was also observed that there was positive correlation between the calorie and protein intake and also improvement in weight and height. All $100 \%$ of mothers as well as Anganwadi workers preferred these supplementary foods better as compared to earlier supplied food i.e. ready to eat food [8].

Studies on Fisher Women in the Coastal Eco System of Andhra Pradesh, Karnataka, Kerala and Tamil Nadu: Two Equipments namely I) Low Cost Ice Cream Freezer, II) Fresh Fish Vending and Display Table have been fabricated and the patents were received on 13th October, 2003. The technology has been licensed to Smt. G. Varalakshmi, W/o. Sri G. Satya Kiran, M/s. Yogi Industries, and Secunderabad for manufacturing these two equipments for a period of two years. She is the sole authority to manufacture in the country. After expiry of two years the technology on low cost ice cream freezer was licensed second time to another women entrepreneur namely Mrs. Lakshmi Bhuvaneswari W/o Devi Hariprasad, D. No. 23/321, Bachupeta, Hindu College Road, Machilipatnam - 527001 on 16th September, 2006 for a period of 6 years. These equipments were fabricated mainly to improve the Health Security [9].

Role of Women in Fisheries in Coastal Eco-System of Andhra Pradesh, Karnataka, Kerala and Tamil Nadu: Fish eaters in the study area comprise 47 per cent of the total population ranging from 237 per cent in Tamil Nadu to 85 per cent in Kerala. Though the position of Tamil Nadu in terms of number of coastal districts and possession of coast line including the number of landing centers is envious, the number of fish eaters in the state is minimal. Andhra Pradesh employs 32 per cent of its fisherwomen in fish curing/drying/net making and 27 per cent in processing plant works [10].

Tribal mother's attitude towards lactation performance: Tribal women are mostly involved in food preparation (25\%) where as men are involved in occupational activities. Majority (85\%) of tribal women do not think lactation as a necessity to take special care about either food because they were lactating. Majority of mothers $(66 \%)$ were aware of the reason for decrease in lactation performance. Only a small number of mothers $(5 \%)$ knew that sickness and insufficient food $(2 \%)$ played a role in decreasing the lactation performance. As nursing mothers, they do not receive any special attention from the family members regarding the additional intake of food. A positive change was observed in lactating mothers through Nutrition Education [11].

Effect of Jawahar Rojgar Yojana Programme during lean season on the Nutritional Status of Women in Landless Labour Families of Drought prone areas: The study was conducted in eight villages of four interior Mandals having low rainfall $(500-750 \mathrm{~mm})$ in Ananthapur a drought prone district of Andhra Pradesh. A household survey was conducted to screen the families having at least one women of child bearing age from the eight selected villages of the four Mandals. A total of 120 families were selected for the study of which 60 families were JRY beneficiary families' where at least one member of the family was being employed under JRY scheme and 60 families were non-JRY beneficiary families. The study showed that the additional income gained by the landless labourer families during the lean season from Jawahar Rojgar Yojana (JRY) programme had beneficial effect on the nutritional status as assessed by the anthropometric measurements as well as clinical observations. The results indicated the past malnutrition status of the population in Ananthapur district because of the repeated and prolonged droughts [12]. Coping mechanisms adapted for food security at household level in drought prone areas of Ananthapur, Andhra Pradesh. A study was carried out in eight villages of four interior Mandals having low rainfall (500-750 mm), in Ananthapur a drought prone district of Andhra Pradesh. Families having at least one women of child-bearing age were enumerated. Two rounds of survey were conducted to understand the difference in coping mechanisms operating between peak and lean seasons. The study centered around the empirical examination of eight major groups of coping mechanisms comprising of land, livestock, economic, food procurement and production, food consumption and distribution, food storage, social and health based mechanisms adapted by the families. The various economic activities under taken by the women in the study area included Agriculture, Agriculture labour, basket making, Beedee making, brick making, broom making, cattle rearing, firewood collection, flour mill, fodder collection, forest produce collection, goat / sheep rearing, laundering, mat weaving, non-agricultural labour, petty trade, pottery, poultry rearing, ring making, sericulture, tailoring, tamarind peeling, vegetable vending and weaving clothes etc. Most often children especially girls were involved in home based trades like groundnut shelling, beedi making, tamarind peeling etc. A few of the mechanisms were found to be beneficial and can be encouraged [13].

Rural Women as Entrepreneurs in Mushroom Cultivation: Every woman is an entrepreneur as she manages, organizes and assures responsibility for running her house. It has been increasingly realized that women possess entrepreneurial talent which can be harnessed to create employment opportunities. In the rural areas a woman can easily manage 4-10 beds depending on the space available, helping them to earn Rs. 180 to Rs.450 per month. The results of the studies revealed that spawn multiplication can be done by women as 
a co-operative venture and mushroom cultivation can be undertaken at household level as an income-generating activity [14]. Recognizing the value and potential of home gardens for enhancing food security and livelihoods, numerous initiates have been launched by governmental, non-governmental, and international organizations in many developing countries that are providing support and building local capacity to enhance the productivity and also for scaling up home garden activities. Overall, the literature review supports the inclusion and promotion of home gardens as an eco-friendly sustainable agricultural practice to improve food security and enhance economic growth.

Family income and nutritional status of pre-scholars' in rural areas of Tenali division: The increase in the annual per capita income of the family increased slightly the nutritional status of pre-scholars. The results also reveal that no significant difference was observed between the body weight of children and income of the parents in all the age group. In spite of having high purchasing power, lower educational status of the mothers and also low nutritional awareness, majority of the children are in Grade 1 degree malnutrition [15]. Transfer of home level preservative techniques of selective fruits and vegetables to rural women in Guntur district: There was a significant, negative correlation between age of the respondents and gain in knowledge. There was a significant positive correlation of socio economic variables such as educational status, family income, and land holding on gain in knowledge [16]. Operational feasibility of RPO supplementation to pre-school children in Anganwadi centers of ICDs Project

Vitamin A deficiency causes many health problems especially among children. A study was undertaken to screen the effect of supplementation of Red Palm Oil (RPO) obtained from the fruits of tree Leis guineensis Jac. The oil is rich in B-carotene, a precursor of Vitamin A. Supplementation of crude RPO to Anganwadi Children increased the attendance of children, increase in heights and weights of children. Decrease in Grade 11 and Grade 111 malnutrition was observed in respect of sex. [17] Impact of women's supplementary income on families' nutritional Status: The Study was carried in 4 villages of Rajendranagar Mandal and Ranga Reddy District (Vegetable venders, Agarbathi labourers, Shopkeepers, Washers, Fruit venders, Tea and Snack workers. The results reveal that the supplementary income of women has a positive impact on socio-economic status of the family. This impact as felt on food and nutrition in take of the family [18].

Impact of dairy program on the nutritional status of women and preschool children in Vihiga District, Kenya Africa: The dairy program in Kenya has a significant impact on the overall improvement of the family in specific to improving production, consumption and marketed surplus of milk. Food and nutrient intake and nutritional status of women and preschool children from participant households improved. The prevalence of under nutrition in pre school children in participant households was lower $(1.7 \%)$ than that of children in non participant households $(2.9 \%)$. Stunting was $8.7 \%$ and $21.4 \%$ in preschool children from participant and non- participant households respectively. Less percent $(6.7 \%)$ of women in participant households had body mass index less than 18.5 , where as $7.3 \%$ of women from nonparticipant households fell below this cut - off point [19].

Success Stories: The National Agricultural Technology Project entitled Studies on Fisherwomen in coastal ecosystem of Andhra Pradesh, Karnataka, Tamil Nadu and Kerala explored the socio-economic status of fisherwomen and found the families wherein women are actively involved in one or other occupation has flourished and achieved all round development. Seven Fisherwomen (3 from Kerala; 2from Karnataka and 2 from A. P) have attained the Training and Awareness from National Agricultural Technology Project, implemented in their places and enhanced their socioeconomic status through various skill oriented training programmes and continuous day-to-day discussions with the Scientists.

\section{Conclusion}

Agricultural interventions are more sustainable in addressing malnutrition among the rural poor than the direct nutritional intervention programs, which may not be costeffective in the long run. To examine this issue, above studies were taken up covering rural households. The scope for interinstitutional linkages among developmental departments to promote nutritional security was also explored. It was proved intervention of various technologies improved the food \& nutritional status of the population. To summarize, agriculture extension viewed as an educational program to be undertaken by public agencies to activate the process of transferring knowledge, science and technology from laboratories to people

Impact of Research / Summary: Based on Vijayakhader work, Commissioner of Horticulture has issued the G. O. on unit cost for Oyster Mushrooms cultivation Rs. 70,000/- by NABARD and implemented from $1^{\text {st }}$ August 1994 onwards (many people have availed the benefit) 41 families have established mushroom cultivation in Guntur, Prakasham and Krishna Districts of Andhra Pradesh; 10 families have taken fruit and vegetable processing at village level; 3 families have adopted the technology of Dehulling jowar and preparing value added products; 10 self help groups have been organized at Karnataka and Kerala are mainly involved in various income generating activities. Mrs Laura Bush, the First Lady of USA had discussions with Mrs Khader on 3rd March 2006 for 2 hours on food processing, income generating activities and gender issues.

Alternative use of millets: The Deccan Development Society (DDS) NGO in Medak District, Andhra Pradesh are using the millet based recipes in feeding program in 8 villages for Anganwadi children (3 to 5 years age).

Technologies Developed ready for commercialization:

Entrepreneurship Technologies: Sorghum Food Enterprise / Geriatric Foods / Malted Infant Foods / High Fiber Vermicelli / Preservation of Palmyra Palm Fruit / Mushroom 


\section{Cultivation.}

Knowledge Empowerment Technologies: Multipurpose fresh fish Vending \& Display Table / Low Cost Ice-cream Freezer

Value Addition Technologies: Value addition to Fruits / Value addition to Red Palm Oil / Fruit Powders / Horse gram Products \& Soya Products.

\section{References}

[1] UNICEF. (1990). Strategy for improved nutrition of children and women in developing countries. A UNICEF policy review. New York: UNICEF.

[2] World Bank. (2013). Improving nutrition through multi-sectoral approaches.

https://www.securenutritionplatform.org/Pages/DisplayResources. aspx?RID $=151$

[3] John Mc Dermett, Myriam, Julien Morel and Nancy Rapando (2013) Agriculture and household nutritive security Development parctie and research needs. Food security, Vol. 5 Issue 5, pp 667-678.

[4] UNICEF (2008), Food Prices increases/Nutrition Security: action for children, the United Nations Children's Fund, New York.

[5] Shetty, P. S. (2009) Incorporating nutritional considerations when addressing food Security. Food Security, 1, 431-440.

[6] Vijayakhader \& P. Ashlesh (1998) Home based low cost energy protein rich preparations using Horse gram (Dolichos Biflorus) for vulnerable groups Indian Oil Palm Journal, Vol. VIII, No. 46, pp. 13-17.

[7] Vijayakhader \& Uma Maheswari K (2012) to study the effect of feeding malted food on the nutritional status of vulnerable groups: accepted for publication in the International Journal for Biotechnology and Molecular Biology Research.

[8] Yasoda Devi \& Vijayakhader (2004) Therapeutic food supplementation in ICDS projects of Andhra Pradesh, Every man's science Vol. 39(3)160-167.

[9] Vijayakhader, R. N. Kumar, J. Lakshmi, K. Dhanapal H. M. Kasim, R. Sathiadas and N. s Sudhakar (2004) Studies on Fisher
Women in the Coastal Eco System of Andhra Pradesh, Karnataka, Kerala and Tamil Nadu, World Fish centre, Global Symposium on Gender and Fisheries Seventh Asian Fisheries forum, P. No. 6979, Penang, Malaysia.

[10] Vijayakhader, R. Sathiadhas and H. Mohammad Kasim (2005) Role of Women in Fisheries in Coastal Eco-System of Andhra Pradesh, Karnataka, Kerala and Tamil Nadu; J. Res ANGRAU 33(1) 53-59.

[11] Vijayakhader, V. Vimala, G. Sarojini and P. Rajyalakshmi (1996) Tribal's of Andhra Pradesh and their Nutritional Status, Book published by Andhra Pradesh Agricultural University, Rajendranagar, Hyderabad-30.

[12] Uma Maheswari K and Vijayakhader (2001) Effect of Jawahar Rojgar Yojana Programme during lean season on the Nutritional Status of Women in Landless Labour Families of Drought prone areas - J. Dairying. Foods \& H. S. 20 (1): 58-61.

[13] Uma Maheswari K. and Vijayakhader (2003) A study on coping mechanisms adopted for food security at Household level in Drought prone areas of Ananthapur, A. P., J. Research ANGRAU, 31(2)127-130.

[14] Vijayakhader (1994) Rural Women as Entrepreneurs in Mushroom Cultivation, Indian Farming, March, 18-21.

[15] Vijayakhader and Kavitha (1993) Anthropometric measurements of pre-school children in the rural areas of Tenali division. Asian Journal of Psychology and Education. Vol. 26 No. 1-2, PP. 35-40.

[16] Vijayakhader and V. V. Bharathi (1994) Transfer of Home level preservative techniques of selective fruit and vegetables to rural women in Guntur district. Asian Journal of Psychology and Education. Vol. 27 No. 3-4, PP. 1-11.

[17] Vijayakhader and Aruna (2008) Operational feasibility of RPO supplementation to pre-school children in Anganwadi centers of ICDs Project, Natural Product Radiance, and Vol. 7 (4) pp 310313.

[18] Vijayakhader (1999) Impact of Women's supplementary incomes as families' Nutritional status. The Indian Journal Social Work, vol. 60(3) 368-378.

[19] Mary Khakoni Walingo and Vijayakhader (2000). Impact of Dairy programme on the Nutritional status of women and preschool children in Vihiga district --- (Ph.D. thesis). 